\title{
Expression Patterns of Growth and Survival Genes with Prognostic Implications in Advanced Pancreatic Cancer
}

\author{
DIMITRIOS PECTASIDES ${ }^{1}$, VASILIKI KOTOULA ${ }^{2,3}$, GEORGE PAPAXOINIS ${ }^{1}$, ZOI ALEXOPOULOU ${ }^{4}$, \\ CHRISTOS DERVENIS $^{5}$, EPAMINONTAS SAMANTAS ${ }^{6}$, KLEO PAPAPARASKEVA $^{7}$, \\ ELPIDA CHARALAMBOUS ${ }^{3}$, CHRYSOULA GKAKOU $^{3}$, CHRISTOS AGALIANOS $^{5}$, \\ KONSTANTINE T. KALOGERAS ${ }^{3,8}$, GEORGE PENTHEROUDAKIS ${ }^{9}$ and GEORGE FOUNTZILAS ${ }^{3}$ \\ ${ }^{1}$ Oncology Section, Second Department of Internal Medicine, Hippokration Hospital, Athens, Greece; \\ ${ }^{2}$ Department of Pathology, Aristotle University of Thessaloniki School of Medicine, Thessaloniki, Greece; \\ ${ }^{3}$ Laboratory of Molecular Oncology, Hellenic Foundation for Cancer Research, \\ Aristotle University of Thessaloniki School of Medicine, Thessaloniki, Greece; \\ ${ }^{4}$ Health Data Specialists Ltd., Athens, Greece; \\ ${ }^{5}$ First Department of Surgery, Konstantopoulio Agia Olga General Hospital, Athens, Greece; \\ ${ }^{6}$ Third Department of Medical Oncology, Agii Anargiri Cancer Hospital, Athens, Greece; \\ ${ }^{7}$ Department of Pathology, Konstantopoulio Agia Olga General Hospital, Athens, Greece; \\ ${ }^{8}$ Translational Research Section, Hellenic Cooperative Oncology Group, Data Office, Athens, Greece; \\ ${ }^{9}$ Department of Medical Oncology, Ioannina University Hospital, Ioannina, Greece
}

\begin{abstract}
Aim: The aim of this study was to evaluate the mRNA expression pattern of growth- and survival-related genes and assess their prognostic significance in patients with advanced pancreatic cancer. Patients and Methods: In total, 98 patients were included in this retrospective translational research study and were evaluated for Kirsten rat sarcoma viral oncogene homolog (KRAS) mutational status, and v-akt murine thymoma viral oncogene homolog 1 (AKT1), AKT serinelthreonine kinase 2 (AKT2), AKT serine/threonine kinase 3 (AKT3), cyclin D1 (CCND1), epidermal growth factor receptor (EGFR), mitogen-activated protein kinase 1 (MAPK1), hepatocellular growth factor receptor (MET), avian myelomatosis viral oncogene homolog (MYC), nuclear factor kappa B subunit 1 (NFKb1), phosphatase and tensin homolog (PTEN) and mechanistic target of rapamycin (FRAP1) genes mRNA expression. Among these patients, 73 received first-line gemcitabine combined with erlotinib $(N=57)$ or gefitinib $(N=16)$. Results: KRAS mutation did not correlate with $m R N A$
\end{abstract}

This article is freely accessible online.

Correspondence to: Professor Dimitrios Pectasides, Oncology Section, Second Department of Internal Medicine, Hippokration Hospital, Athens 115 27, Greece. Tel: +30 2107774742, e-mail: pectasid@otenet.gr; hecogoff@otenet.gr

Key Words: Pancreatic cancer, KRAS, EGFR, prognosis, hierarchical clustering analysis, mRNA expression. gene expression. Unsupervised hierarchical clustering according to mRNA gene expression successfully distinguished four prognostically distinct groups of tumors. Overexpression of all genes was associated with best prognosis, while suppression or heterogeneous expression patterns of the examined genes were associated with expression patterns of growth- and survival-related genes, classifying pancreatic tumors into distinct groups with possibly different outcomes.

The epidermal growth factor receptor (EGFR) pathway has a major importance in pancreatic cancer(1). Erlotinib, a tyrosine kinase inhibitor (TKI) of EGFR, was tested in combination with gemcitabine as first-line treatment in a randomized trial of patients with advanced pancreatic cancer (2). The addition of erlotinib to gemcitabine demonstrated a modest but statistically significant survival benefit. Therefore, the identification of biomarkers for the selection of patient subgroups with a more meaningful benefit from erlotinib is mandatory. Multiple parameters, such as Kirsten rat sarcoma viral oncogene homolog (KRAS) mutations, $E G F R$ gene copy number alterations, protein expression and polymorphisms and phosphatase and tensin homolog (PTEN) protein expression have been examined in the populations of the PA.3 (2) and AIO-PK0104 (3) randomized trials. Unfortunately, none demonstrated predictive significance for benefit from EGFR modulation, whereas the results about their prognostic role were conflicting (4-8). Consequently, no specific molecular alteration has been found to predict response to EGFR inhibitors (9). 
Moreover, to our knowledge, no published study has examined the prognostic/predictive significance of growth and survival pathway gene-expression profiling in patients with pancreatic cancer treated with EGFR inhibitors. Among such genes, the most important is KRAS, which has been found to be mutated in approximately $70-90 \%$ of cases (5). EGFR and AKT serine/threonine kinase 2 (AKT2) amplification, and PTEN deletion are other important genetic aberrations. Increased AKT pathway activity has been found in up to $60 \%$ of pancreatic cancer tissues and cell lines. Murine leukemia viral oncogene (RAF)- mitogen-activated protein kinase (MAPK) and phosphatidylinositol-4,5-bisphosphate 3-kinase

(PI3K)-AKT pathway activation lead to up-regulation of cyclin D1 (CCND1) and avian myelomatosis viral oncogene homolog $(M Y C)$ transcription and activity and to stimulation of the nuclear factor kappa B subunit (NFkB) pathway (1, 10, 11). $M Y C$ overexpression is extremely common in pancreatic cancer tissues, while low amplification occurs in approximately $30 \%$ of cases (12). CCND1 overexpression has been reported in $65-80 \%$ of pancreatic adenocarcinomas and has been associated with poor prognosis, whereas amplification was observed in $20 \%$ (13). The hepatocellular growth factor receptor (MET) receptor is overexpressed in pancreatic cancer, while the hepatocellular growth factor (HGF)/MET pathway is stimulated mostly by hypoxia. MET signaling is mediated mainly by the RAF-MAPK and PI3KAKT pathways and seems to confer resistance to EGFR TKIs $(10,11)$. In view of the complexity of the accumulating preclinical data, we sought to retrospectively examine the correlation and significance of tissue mRNA levels of $A K T 1$, AKT2, AKT3, CCND1, EGFR, MAPK1, MET, MYC, NFKB1, $P T E N$ and mechanistic target of rapamycin (FRAPl) and $K R A S$ mutational status in patients with pancreatic cancer treated with an EGFR TKI in the context of two prospective studies.

\section{Patients and Methods}

Patient population. Inclusion criteria were metastatic or locally advanced pancreatic cancer treated with first-line gemcitabine and erlotinib or gefitinib (prognostic cohort) or surgically resected pancreatic cancer treated with adjuvant gemcitabine or a fluoropyrimidine (molecular epidemiology cohort). In total, 98 patients with pancreatic adenocarcinoma treated from May 2001 to February 2011 in four Hellenic Cooperative Oncology Group (HeCOG) centers, available clinical data and formalin-fixed paraffin-embedded (FFPE) tumor tissue of sufficient RNA quality and quantity to obtain informative results for at least one biomarker were included in the study. Seventy-three had advanced unresectable and 25 surgically resected tumors. Gefitinib was administered in the context of a phase II single-arm trial of advanced pancreatic cancer (14), while erlotinib was given within an observational cohort study for advanced disease. The Reporting Recommendations for Tumor Marker Prognostic Studies (REMARK) flow chart of the study is shown in Figure 1.
Translational research study. This retrospective translational research study was approved by the HeCOG Protocol Review Committee and the Institutional Review Board of the Papageorgiou General Hospital (Approval number 649). The study complied with the REMARK recommendations for tumor marker prognostic studies using biological material (15). All patients signed an informed consent form for the provision of biological material for future research purposes.

Molecular methods. FFPE tumor tissue blocks from the 98 patients with pancreatic adenocarcinoma were processed for RNA extraction, following histological examination to estimate tumor tissue abundance. In order to enrich the molecular template with tumor transcripts, manual macrodissection was performed in cases with $<50 \%$ tumor cell content; of note, such macrodissected samples also unavoidably contained tumor stroma. Upon macrodissection, tissue sections were transferred into a lysis buffer containing $500 \mu \mathrm{g} / \mathrm{ml}$ proteinase $\mathrm{K}$ for overnight lysis at $56^{\circ} \mathrm{C}$. Total RNA was isolated from tissue lysates with TRIZOL-LS (Invitrogen/Life Technologies, Paisley, UK), according to the manufacturer's instructions. Following UV measurements, 4-5 $\mu \mathrm{g}$ of total RNA were reverse transcribed with random hexamers and SuperScript ${ }^{\circledR}$ III Reverse Transcriptase (all reagents from Invitrogen/Life Technologies, Carlsbad, CA, USA). Once cDNAs were normalized at $25 \mathrm{ng} / \mu \mathrm{l}$, relative mRNA expression was assessed with quantitative polymerase chain reaction (qPCR) in an ABI7900HT system under default conditions. The following exonspanning premade Taqman-MGB assays (Applied Biosystems/Life Technologies, Paisley, UK) were selected for the mRNA targets under investigation (data in parentheses refer to assay ID; Genbank reference; amplicon location; size): AKT1 (Hs00178289_m1; NM_001014431.1, NM_001014432.1, NM_005163.2; exons 4-5, 56, 4-5; 66 bp), AKT2 (Hs00609846_m1; NM_001626.3; exons 1-2; 129 bp), AKT3 (Hs00178533_m1; NM_181690.1, NM_005465.3; exons 10-11; 100 bp), CCND1 (Hs00765553_m1; NM_053056.2; exons 3-4; 57 bp), EGFR (Hs00193306_m1; NM_005228.3; exons 20-21; 69 bp), MAPK1 (Hs01046830_m1; NM_138957.2, NM_002745.4; exons 6-7; 74 bp), MET (Hs00179845_m1; NM_001127500.1, NM_000245.2; exons 10-11; 81 bp), MYC (Hs00153408_m1; NM_002467.4; exons 2-3; 107 bp), NFKB1 (Hs00231653_m1; NM_001165412.1, NM_003998.3; exons 19-20; 73 bp), PTEN (Hs02621230_s1; NM_000314.4; exons 9-9; 135 bp) and FRAP1 (Hs00234508_m1; NM_004958.3; exons 20-21; 103 bp).

Samples were processed in $10 \mu \mathrm{l}$ reactions $(50 \mathrm{ng}$ cDNA/reaction) with TaqMan ${ }^{\circledR}$ Universal PCR Master Mix and run in duplicates in 384-well plates. As a positive control, a commercially available reference RNA (TaqMan ${ }^{\circledR}$ Control Total RNA, cat. no 4307281, Applied Biosystems/Life Technologies) was included in each run. Moreover, a Taqman-MGB expression assay targeting $\beta$-glucuronidase (GUSB) mRNA (Hs00939627_m1; NM_000181.3; exons 8-9: 96 bp) was used as an endogenous control and for the normalization of cycle threshold (CT) values. Relative quantification (RQ) was assessed in a linear mode as (40$\triangle \mathrm{CT})$, whereby $\Delta \mathrm{CT}=($ avg CT target $)-($ avg CT GUSB $)$. Exclusion criteria from RQ analysis were GUSB CT values higher than 36 and duplicate $\Delta \Delta \mathrm{CT}$ of $>0.8$ in the same run, whereas PCR assay stability was evaluated among runs with the reference RNA.

Methods of DNA extraction and KRAS mutation assessment. DNA extraction was performed from macrodissected tissue fragments as above, with the QIA amp DNA Mini Kit (Qiagen, Hilden, 


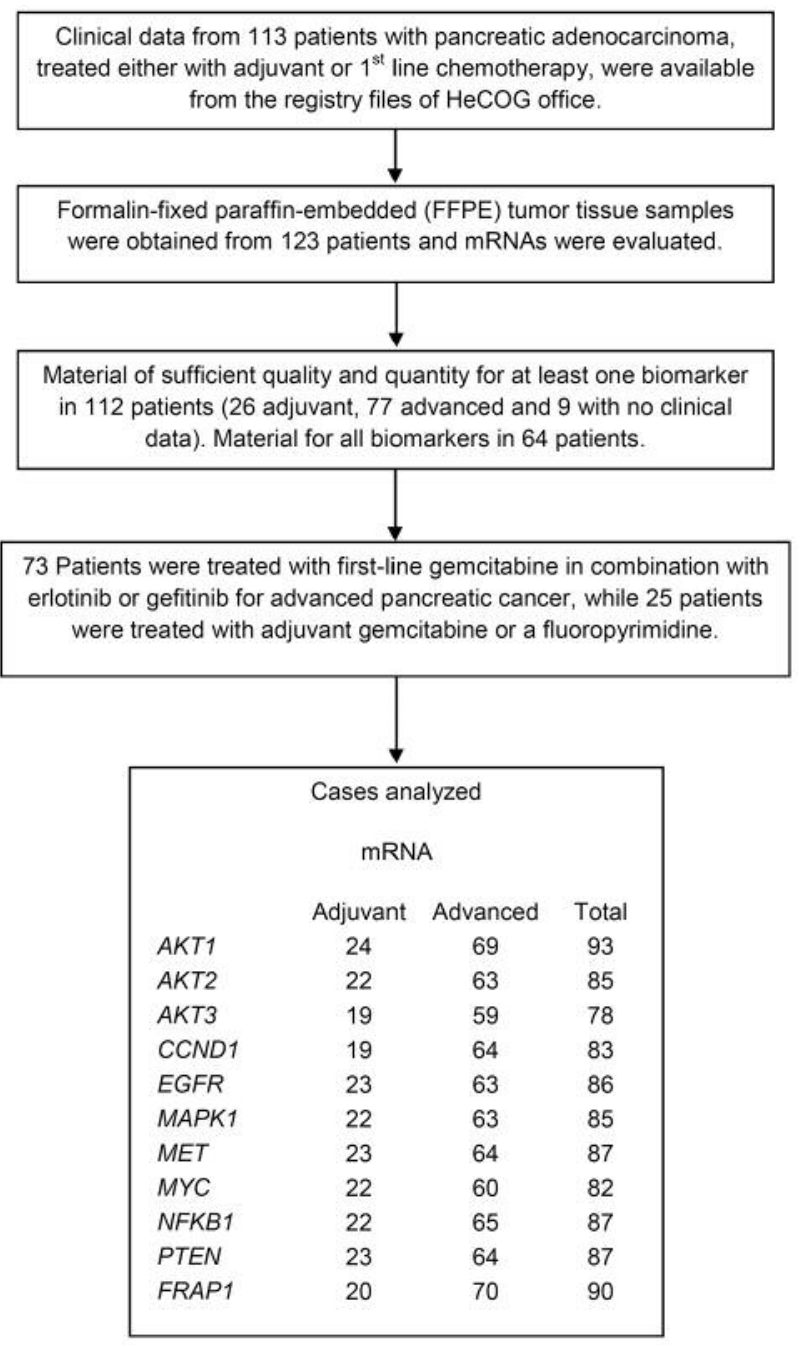

Figure 1. REMARK flow chart.

Germany), according to the manufacturer's instructions. KRAS mutations (exons 2,3,4) were assessed with dd-sequencing on nested PCR amplicons. Primers were located in adjacent introns spanning the entire coding regions of interest and are available upon request. Nested primers were coupled with universal M13 forward and reverse primers at the 5 '-end. Sense and antisense sequencing was performed using M13 forward and reverse primers in $10 \mu \mathrm{l}$ reactions with the Big Dye Terminator kit v.1.1 (Applied Biosystems/Life Technologies). Products were visualized upon capillary electrophoresis in an ABI3130XL genetic analyzer, base called and further analysed with Sequencing Analysis version 5.2 software (Applied Biosystems).

Statistical analysis. Comparisons of categorical with continuous variables were made using the Mann-Whitney or the KruskalWallis tests, while the Fisher's exact test was used for testing associations between categorical variables. Pearson's correlation coefficients were used to assess correlations among continuous variables. Separation of the continuous data for markers into high and low expression groups was performed using the median cut-off.

For the patients with advanced cancer, progression-free survival (PFS) was measured from the time of initiation of first-line treatment until verified disease progression, death or last contact (whichever occurred first), while overall survival (OS) was measured from the time of initiation of first-line treatment until death from any cause or date of last contact. For the adjuvantly treated patients, disease-free survival (DFS) and OS were measured from the date of initiation of adjuvant treatment. Time-to-event distributions were estimated using Kaplan-Meier curves, while logrank tests and univariate Cox analyses were used for assessing differences statistically and reporting hazard ratios, respectively.

Unsupervised hierarchical clustering (using Ward's minimum variance method) was conducted for the mRNA markers in order to identify distinct groups correlating with prognosis. Multivariate analysis was not performed because the sample size was too small. All tests were two-sided. The statistical analysis complied with the reporting recommendations for tumor marker prognostic studies (15) and was performed usingSAS software (SAS for Windows, version 9.3; SAS Institute Inc., Cary, NC, USA).

\section{Results}

Basic patient and disease characteristics. Basic patient and disease characteristics are depicted in Table I. Among those with advanced pancreatic cancer, 53 patients $(72.6 \%)$ were initially diagnosed with metastatic disease, while the rest with earlier stages. Fifty-seven patients were treated with gemcitabine-erlotinib and 16 with gemcitabine-gefitinib. The median number of cycles was 6 for patients with advanced disease and 6 for those treated with adjuvant chemotherapy (range $=1-16$ and 1-27, respectively).

Response to treatment and survival. Survival data were available for 15 patients with resected disease and for 70 with advanced disease. The median follow-up for adjuvantly treated patients was 40.5 months, while for those with advanced disease, it was 6.1 months (range=2.6-71.8 and 0.5-32.2, respectively). By the last date of follow-up, 11 out of the 15 patients treated with adjuvant chemotherapy had experienced disease relapse, with a median DFS of 15 months and 1-year DFS of $60 \%$. Nine patients had died, with a median OS of 23 months and 1-year OS of 73.3\%. Among the 70 patients with advanced disease, in 61 disease had progressed and 56 had died, with a median PFS and OS of 5 and 7 months, respectively, and a 1-year PFS and OS of $7.6 \%$ and $30 \%$, respectively. Only four patients responded to treatment (response rate $=5.4 \%$ ).

mRNA expression studies. RQ values of gene expression were obtained for 98 patients in total, 93 patients for $A K T 1$, 85 for $A K T 2,78$ for $A K T 3,83$ for $C C N D 1,86$ for $E G F R$, 85 for $M A P K 1,87$ for $M E T, 82$ for $M Y C, 87$ for $N F K B 1$, 87 for $P T E N$ and 90 for FRAPl. Figure 1 shows the REMARK flow chart of the present study and the numbers 
Table I. Patient and disease characteristics.

\begin{tabular}{llcc}
\hline & & & Group \\
\cline { 3 - 4 } & & Adjuvant & Advanced \\
\hline Patients & N & 25 & 73 \\
Age, years & Mean (SD) & $62.2(10.8)$ & $63.4(11)$ \\
Karnofsky PS & Min-Max & $42-77$ & $36-80$ \\
Gender, n (\%) & Median & $90 \%$ & $80 \%$ \\
Histological grade, n (\%) & Female & $7(28)$ & $27(37)$ \\
& Male & $18(72)$ & $46(63)$ \\
TNM stage at diagnosis, $n(\%)$ & G3, G4, GX & $13(52)$ & $35(48)$ \\
& Not reported & $12(48)$ & $23(32)$ \\
& I & $3(12)$ & $15(21)$ \\
& II & $19(76)$ & $1(1.4)$ \\
& III & $2(8)$ & $10(14)$ \\
& IV & $0(0)$ & $6(8)$ \\
\end{tabular}

PS: Performance status.

that correspond to the 98-patient cohort. The majority of available tissues were from the pancreatic primary site $(\mathrm{N}=77,78.6 \%)$, seven $(7.1 \%)$ were from regional lymph nodes and $13(13.3 \%)$ from distant metastatic sites, while in one $(1.0 \%)$, the site of origin was not reported. Among 73 patients with advanced disease treated with gemcitabine and an EGFR TKI, nine (12.3\%) had tissue available only from prior surgery, while tissue samples were available from biopsies in remaining cases. RQ gene expression levels in patients with advanced disease are shown in Figure 2 .

Correlations. Significant correlations $(p<0.0001)$ were found most frequently with MAPK1, NFKB1 and CCND1. The strongest correlations (correlation coefficient $\geq 0.6$ ) were observed for $M A P K 1$ with $N F K B 1$, and for $M A P K 1$ with $P T E N$, as shown in Table II.

Correlations between marker RQ levels and age, gender and histological grade were also tested. Males had relatively higher levels of mRNA expression of CCNDI (median RQ: 44.2 vs. 43.6, $p=0.027$ ), EGFR (median RQ: 40.4 vs. 40.0, $p=0.042$ ) and MET (median RQ: $41.3 v s .40 .5, p=0.045$ ). In addition, patients $\geq 60$ years old had higher levels of mRNA expression of MAPK1 (median RQ: $41.7 v s .41 .4, p=0.046$ ), MET (median RQ: $41.5 v s .40 .5, p=0.015$ ), NFKB1 (median RQ: 40.3 vs. 39.9, $p=0.013$ ) and PTEN (median RQ: $40.2 v s$. $39.5, p=0.011)$.

KRAS mutations and their correlation with gene expression. $K R A S$ mutations were evaluated in 80 patients, 58 with advanced- and 22 with early-stage disease. Among them,
Table II. Significant correlations (all $p<0.0001$ ) between relative quantification $(R Q)$ values for expression of the genes studied.

\begin{tabular}{lccccc}
\hline Variable & $\begin{array}{c}\text { With } \\
\text { variable }\end{array}$ & $\mathrm{N}$ & $\begin{array}{c}\text { Correlation } \\
\text { coefficient }\end{array}$ & $\begin{array}{c}\text { Lower 95\% } \\
\text { confidence } \\
\text { limit }\end{array}$ & $\begin{array}{c}\text { Upper 95\% } \\
\text { confidence } \\
\text { limit }\end{array}$ \\
\hline AKT1 & CCND1 & 95 & 0.50 & 0.33 & 0.64 \\
& MAPK1 & 97 & $\mathbf{0 . 5 9}$ & 0.44 & 0.70 \\
& NFKB1 & 98 & $\mathbf{0 . 5 3}$ & 0.37 & 0.66 \\
CCND1 & $E G F R$ & 91 & 0.50 & 0.33 & 0.64 \\
& $M A P K 1$ & 91 & $\mathbf{0 . 5 7}$ & 0.41 & 0.69 \\
& $M E T$ & 93 & 0.50 & 0.33 & 0.64 \\
& NFKB1 & 92 & $\mathbf{0 . 5 6}$ & 0.40 & 0.68 \\
EGFR & $P T E N$ & 93 & $\mathbf{0 . 5 6}$ & 0.40 & 0.68 \\
& $M A P K 1$ & 94 & 0.44 & 0.25 & 0.59 \\
MAPK1 & NFKB1 & 95 & 0.46 & 0.28 & 0.60 \\
& $M E T$ & 97 & 0.44 & 0.26 & 0.58 \\
& $M Y C$ & 91 & 0.45 & 0.27 & 0.60 \\
& NFKB1 & 94 & $\mathbf{0 . 7 8}$ & 0.68 & 0.84 \\
MET & $P T E N$ & 95 & $\mathbf{0 . 6 1}$ & 0.47 & 0.72 \\
MYC & NFKB1 & 96 & 0.46 & 0.28 & 0.60 \\
& NFKB1 & 92 & $\mathbf{0 . 5 9}$ & 0.44 & 0.71 \\
NFKB1 & $P T E N$ & 93 & 0.40 & 0.21 & 0.55 \\
\hline
\end{tabular}

The strongest Pearson's correlation coefficients $(>0.5)$ are shown in bold.

KRAS mutations were detected in 56 patients (70\%), 38 $(65.5 \%)$ with advanced-stage and $18(81.8 \%)$ with earlystage. The types of KRAS mutations and their frequencies are reported in Table III. KRAS mutations were not correlated with mRNA RQ values of any of the genes under study. 


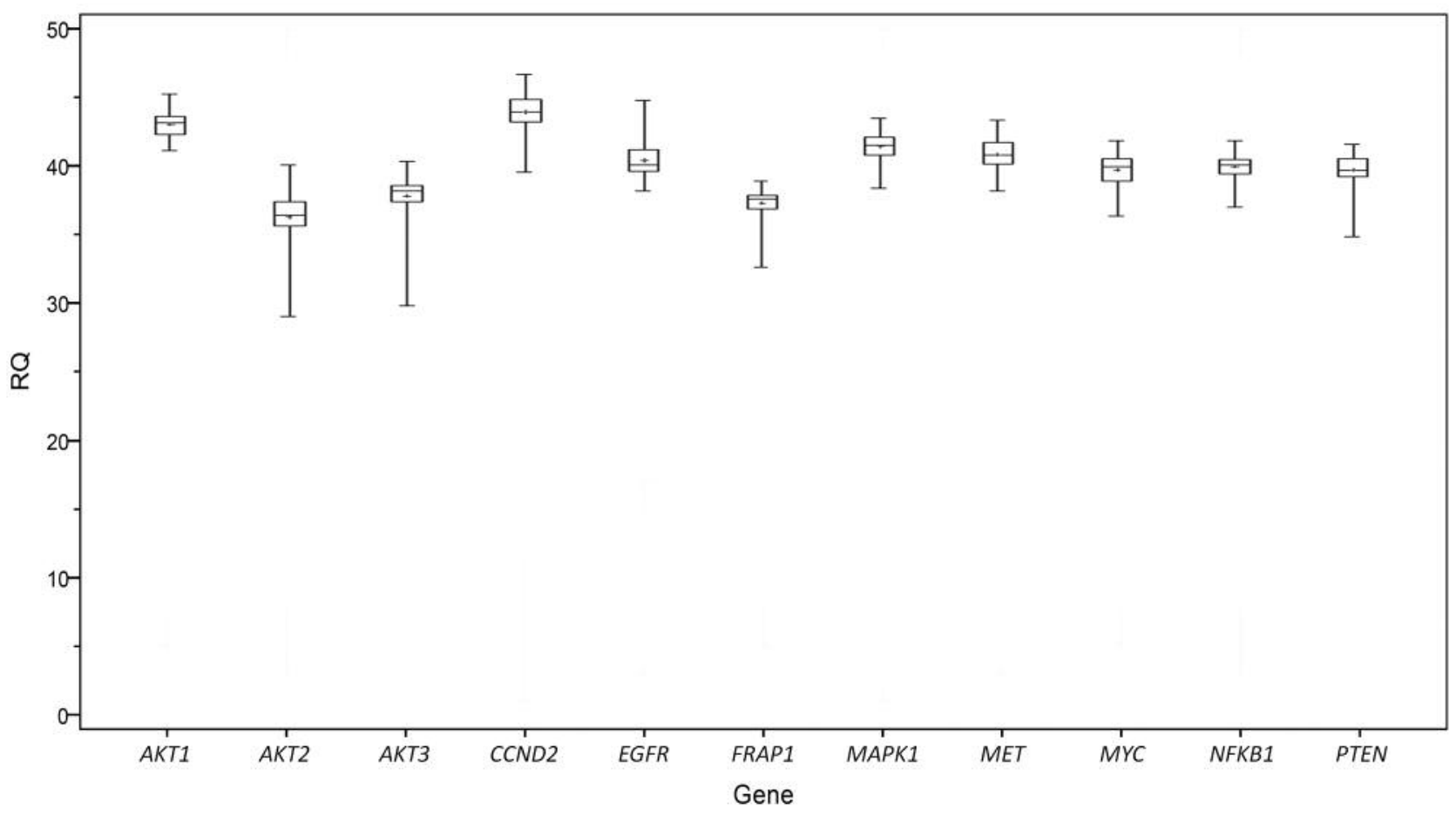

Figure 2. Boxplot for the relative quantification $(R Q)$ gene expression levels (patients with advanced cancer stage).

Prognostic factor analysis. Prognostic factor analysis was only performed for patients with advanced pancreatic cancer because of the low number of patients treated with adjuvant chemotherapy with available survival data. Univariate analysis of prognostic factors for advanced disease showed only a marginally significant favorable effect of high NFKB1 mRNA RQ level on PFS (7vs. 4 months, $p=0.0495$ ). AKT3 levels above the median were associated with marginally significantly higher response rate $(14.3 \%$ vs. $0.0 \%, p=0.045)$. Interestingly, KRAS mutational status did not significantly influence PFS or OS, nor the objective response rate.

Hierarchical clustering analysis. In patients with advanced pancreatic cancer, gene-expression signatures were created by clustering, a statistical method that classifies tumors into groups, according to their gene expression RQ values, in order to achieve the highest similarity within groups and the highest distinction between groups. Clustering is not influenced by parameters, such as response or survival. Clustering into 2, 3 or 4 groups was attempted and as expected, clustering into four groups more successfully distinguished tumors into distinct clusters (Figure 3). Clusters 1 and 2 were characterized by predominantly high or low gene-expression levels, respectively. In cluster 1, gene expression followed a more 'normal' distribution, with relatively high EGFR mRNA expression. Cluster 2 was
Table III. Types of Kirsten rat sarcoma viral oncogene homolog (KRAS) mutations and their frequencies.

\begin{tabular}{|c|c|c|c|c|c|c|}
\hline & & & \multicolumn{4}{|c|}{ Group } \\
\hline & \multicolumn{2}{|c|}{ Total } & \multicolumn{2}{|c|}{ Adjuvant } & \multicolumn{2}{|c|}{ Advanced } \\
\hline & $\mathrm{N}$ & $\%$ & $\mathrm{~N}$ & $\%$ & $\mathrm{~N}$ & $\%$ \\
\hline \multicolumn{7}{|l|}{ KRAS } \\
\hline Mutated & 56 & 70.0 & 18 & 81.8 & 38 & 65.5 \\
\hline WT & 24 & 30.0 & 4 & 18.2 & 20 & 34.5 \\
\hline Total & 80 & 100.0 & 22 & 100.0 & 58 & 100.0 \\
\hline \multicolumn{7}{|c|}{$K R A S$ mutation type } \\
\hline p.G12C & 10 & 17.9 & 2 & 11.1 & 8 & 21.1 \\
\hline p.G12D & 28 & 50.0 & 8 & 44.4 & 20 & 52.6 \\
\hline p.G12R & 4 & 7.1 & 0.0 & 0.0 & 4 & 10.5 \\
\hline p.G12V & 14 & 25.0 & 8 & 44.4 & 6 & 15.8 \\
\hline Total & 56 & 100.0 & 18 & 100.0 & 38 & 100.0 \\
\hline
\end{tabular}

WT: Wild-type.

characterized by low expression of the majority of markers and moderate expression of AKT2 and MET. In cluster 3, the studied genes had extremely low mRNA expression. The receptors $E G F R$ and $M E T$, the mediators $A K T 1$ and $M A P K 1$, the regulatory molecule $N F K B 1$, the inhibitory factor PTEN and the downstream effectors $M Y C$ and CCND1, all 


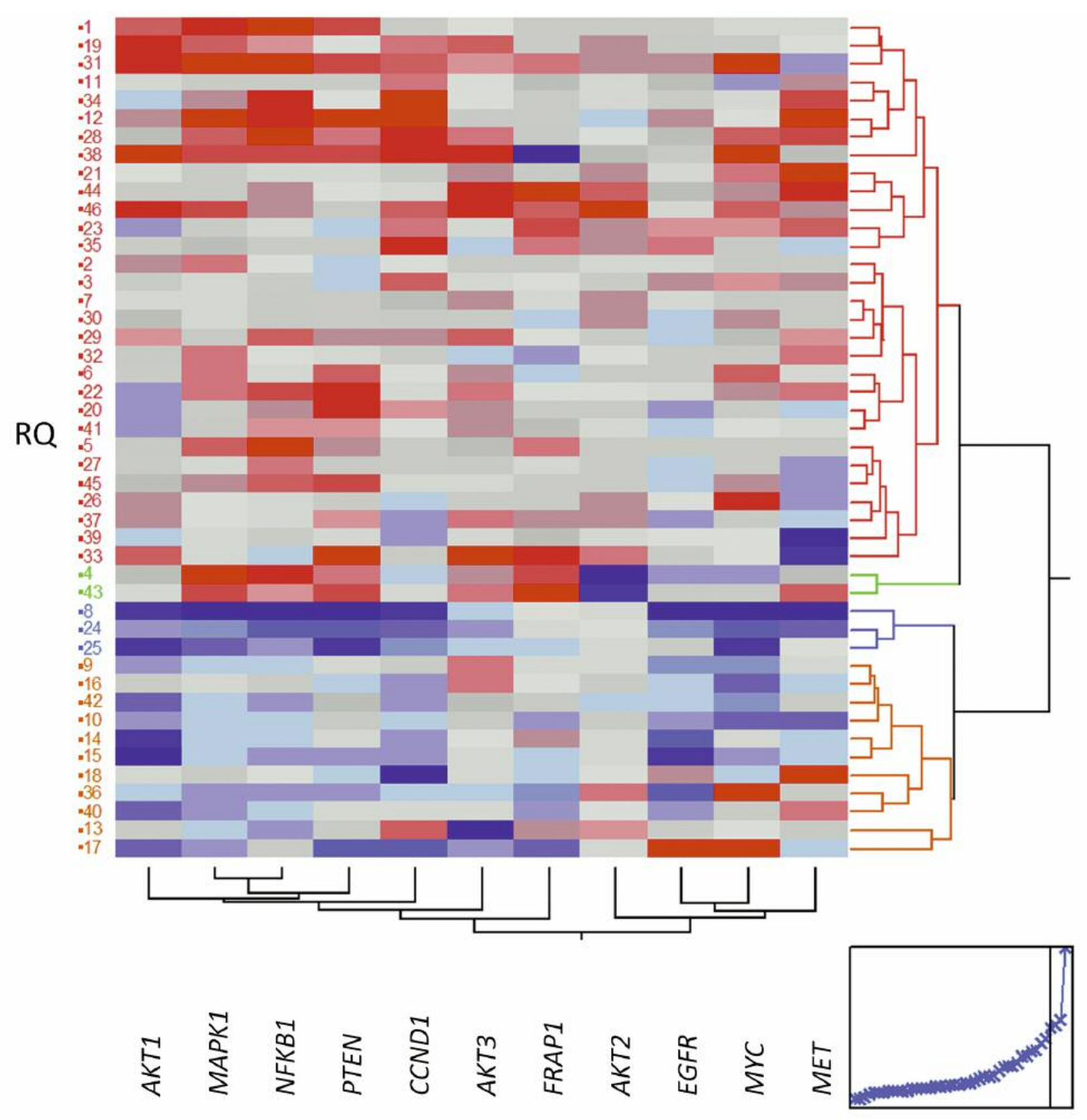

Figure 3. Unsupervised hierarchical clustering into four groups of relative quantification (RQ) values. Heatmap of the four clusters: Cluster 1, red $(n=30)$; Cluster 2, orange ( $n=11)$; Cluster 3, blue ( $n=3)$; Cluster 4 , green $(n=2)$. High $R Q$ values are red and low values blue.

Table IV. Median overall (OS) and progression-free (PFS) survival for each cluster of patients.

\begin{tabular}{lccccc}
\hline Standardized clustering & $\mathrm{N}$ & Median OS (months) & $95 \% \mathrm{CI}$ & Median PFS (months) & 95\% CI \\
\hline Cluster 1 & 30 & 8.3 & $5.2-13.8$ & 5.7 & $3.4-7.5$ \\
Cluster 2 & 11 & 6.5 & $1.4-18.7$ & 4.1 & $1.4-8.1$ \\
Cluster 3 & 3 & 6.9 & $4.0-9.8$ & 4.0 & $1.4-5.1$ \\
Cluster 4 & 2 & 2.8 & $2.6-2.9$ & 1.9 & $1.1-2.6$ \\
\hline
\end{tabular}

CI: Confidence interval. 

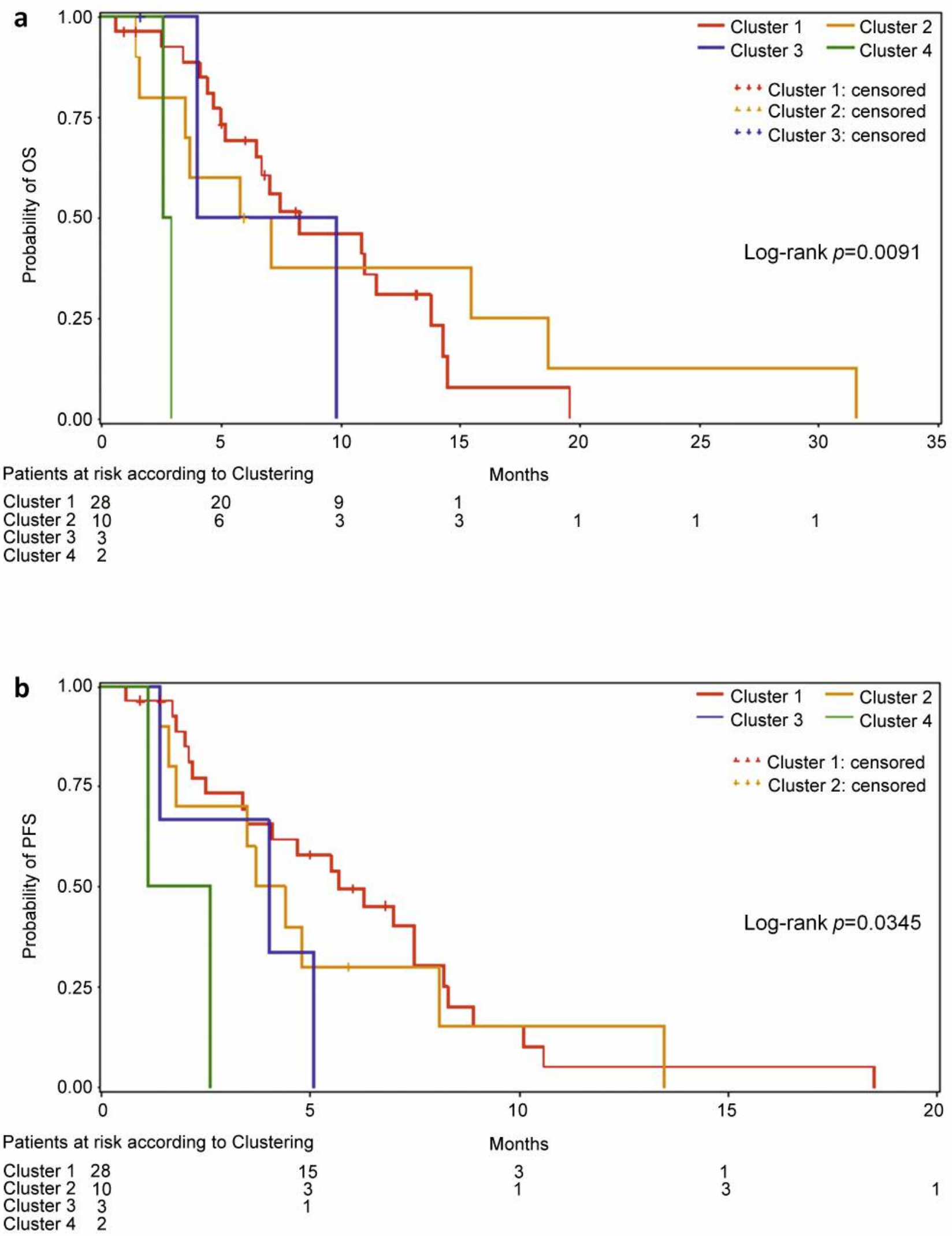

Figure 4. Overall (OS) (a) and progression-free (PFS) (b) survival for the four patient clusters. 
demonstrated markedly low expression. Cluster 4 included only two cases, which may represent outliers or a true biologically separate subset. The predominant common feature of these two cases was the distinct gene-expression pattern, with elevated expression of MAPK1, PTEN, NFKB1, FRAP1, AKT3 and MET and relatively lower mRNA RQ levels of $A K T 2, M Y C$ and $C C N D 1$.

The median OS and PFS were calculated for each cluster (Table IV). Interestingly, patients with tumors expressing predominantly high transcript levels of the genes examined (cluster 1) seemed to have the best OS and PFS (log-rank, $p=0.009$ and $p=0.035$, respectively), although the number of patients was too low to draw definitive conclusions (Figure 4).

\section{Discussion}

Pancreatic adenocarcinoma is an aggressive malignancy, relatively resistant to antineoplastic treatment. Until now, it has been approached as a single disease entity and treatment decisions were based on clinical criteria only, such as stage, age and performance status. Recent research has focused on subclassifying tumors into groups according to prognostic/predictive biomarkers in order to better understand disease biology and ultimately improve treatment, with significantly heterogeneous results (16-19). Numerous prognostic biomarkers have been described but a significant proportion of them have been studied in pancreatectomy specimens from patients mostly treated with postoperative chemotherapy $(17,18,20,21)$. In contrast, translational research studies in patients treated with newer agents, such as EGFR inhibitors, are scarce and only a small number of biomarkers has been tested.

In the present study, about $75 \%$ of the patients were treated with gemcitabine plus an EGFR TKI (erlotinib or gefitinib) for advanced disease. The rest underwent resection of localized disease and received adjuvant chemotherapy, mostly gemcitabine monotherapy. This adjuvant cohort was included in the study in order to enrich our molecular epidemiology data regarding the expression pattern of multiple genes of the growth and survival pathways.

Some of these genes are known to be primarily affected, such as EGFR, AKT2, CCND1 and MYC by amplification, and PTEN by deletion. Although most of the studied biomarkers had demonstrated prognostic significance in previous studies, this was not the case in our study. Moreover, in contrast to the literature $(22,23), N F K B 1$ was shown to have marginally favorable prognostic significance (21). This could easily be attributed to the small size of the patient population, although two significant factors should be considered. The first is that these biomarkers had almost exclusively been previously studied by immunohistochemistry $(1,11-13,22-24)$, and not mRNA expression. The second is that most of the factors had never been studied in patients treated with EGFR inhibitors
(1, 11-13). In our study, the absence of a control group of patients with advanced pancreatic cancer not receiving EGFR inhibitors with chemotherapy makes it impossible to dissect potential prognostic from predictive significance. It could be hypothesized that some biomarkers might have adverse prognostic and favorable predictive utility in the presence of erlotinib or gefitinib, the latter diluting the former in the absence of a control group.

The prognostic versus predictive significance of any given biomarker can only be investigated in a randomized trial. Although the translational research results of the PA.3 and AIO-PK0104 studies were negative for the predictive and conflicting for the prognostic significance of a limited number of biomarkers (4-6), the existence of significant correlations in their expression levels, as shown in our study, probably reflects the complexity of tumor biology. This could explain the negative results and may only be overcome by studying genetic signatures rather than single molecular alterations.

In a study of pancreatic adenocarcinoma xenograft models, Jimeno et al. studied mRNA expression, mutations, copy number changes and protein expression of multiple EGFR pathway genes. Interestingly, neither genetic alterations nor immunohistochemistry predicted sensitivity to EGFR inhibitors. On the other hand, global increase in the expression and activation of the EGFR pathway-related genes accurately predicted drug efficacy (22).

In our study, multigene expression was able to discriminate patients with advanced pancreatic tumors into four clusters, with similar expression patterns within-clusters for most of the studied genes. Cluster 1 was characterized by a homogeneously high gene expression pattern. This globally increased expression may be a surrogate marker of an EGFR pathway addiction of the tumor and a possible sensitivity to EGFR inhibitors. In contrast, clusters 2 and 3 demonstrated moderate and extremely low expression of most of the genes, respectively. The marked down-regulation of most of the genes in cluster 3 may reflect dependence on other growth and survival pathways. Finally, cluster 4 showed a heterogeneous gene expression pattern, with up-regulation of genes, such as MAPK1, NFKB1, PTEN, FRAP1 and MET, not known to be commonly altered in pancreatic cancer. Their high relative expression may result from other genetic alterations that influence MET expression, as well as from the PI3K-AKT-mTOR and MAPK-NFkB pathways.

Survival analysis showed that patients of clusters 1 and 2 had statistically longer OS and PFS than those of clusters 3 and 4 , although the small sample size does not allow for any definitive conclusion to be drawn. The rarity of responses precluded any analysis for prediction of objective tumor regression. However, considering the observations of Jimeno et al. (22), global overexpression of the present gene set may be associated with favorable prognosis due to a relatively better responsiveness to EGFR inhibitors. Notably, Collisson et al. 
found that their favorable prognosis gene-expression signature was also associated with higher sensitivity to erlotinib but lower sensitivity to gemcitabine, although the EGFR pathway family was underrepresented in their gene set (16).

\section{Conclusion}

In the current study, we report on the emergence of geneexpression signatures with potential prognostic significance in a cohort of patients with advanced pancreatic cancer homogeneously managed with the combination of gemcitabine and an EGFR TKI. This study supports the concept that gene-expression signatures may better reflect the complexity of pancreatic adenocarcinoma biology and possibly offer useful prognostic or even predictive information. Nevertheless, these results should be confirmed and validated in larger independent cohorts.

\section{Conflicts of Interest}

The Authors declare that they have no competing interests. The funders had no role in study design, data collection and analysis, decision to publish, or preparation of the manuscript.

\section{Funding}

This study was supported by an internal Hellenic Cooperative Oncology Group (HeCOG) translational research grant (HE R_3/10).

This study was also partly supported by the Hellenic Study Group for Liver Metastatic Disease.

\section{References}

1 Troiani T, Martinelli E, Capasso A, Morgillo F, Orditura M, De Vita $\mathrm{F}$ and Ciardiello F: Targeting EGFR in pancreatic cancer treatment. Curr Drug Targets 13: 802-810, 2012.

2 Moore MJ, Goldstein D, Hamm J, Figer A, Hecht JR, Gallinger S, Au HJ, Murawa P, Walde D, Wolff RA, Campos D, Lim R, Ding K, Clark G, Voskoglou-Nomikos T, Ptasynski $M$ and Parulekar W; National Cancer Institute of Canada Clinical Trials Group: Erlotinib plus gemcitabine compared with gemcitabine alone in patients with advanced pancreatic cancer: a phase III trial of the National Cancer Institute of Canada Clinical Trials Group. J Clin Oncol 25: 1960-1966, 2007.

3 Heinemann V, Vehling-Kaiser U, Waldschmidt D, Kettner E, Märten A, Winkelmann C, Klein S, Kojouharoff G, Gauler TC, von Weikersthal LF, Clemens MR, Geissler M, Greten TF, Hegewisch-Becker S, Rubanov O, Baake G, Höhler T, Ko YD, Jung A, Neugebauer S and Boeck S: Gemcitabine plus erlotinib followed by capecitabine versus capecitabine plus erlotinib followed by gemcitabine in advanced pancreatic cancer: final results of a randomised phase 3 trial of the 'Arbeitsgemeinschaft Internistische Onkologie' (AIO-PK0104). Gut 62: 751-759, 2013.

4 da Cunha Santos G, Dhani N, Tu D, Chin K, Ludkovski O, Kamel-Reid S, Squire J, Parulekar W, Moore MJ and Tsao MS:
Molecular predictors of outcome in a phase 3 study of gemcitabine and erlotinib therapy in patients with advanced pancreatic cancer: National Cancer Institute of Canada Clinical Trials Group Study PA.3. Cancer 116: 5599-5607, 2010.

5 Boeck S, Jung A, Laubender RP, Neumann J, Egg R, Goritschan C, Ormanns S, Haas M, Modest DP, Kirchner T and Heinemann $\mathrm{V}$ : KRAS mutation status is not predictive for objective response to anti-EGFR treatment with erlotinib in patients with advanced pancreatic cancer. J Gastroenterol 48: 544-548, 2013.

6 Boeck S, Jung A, Laubender RP, Neumann J, Egg R, Goritschan C, Vehling-Kaiser U, Winkelmann C, Fischer von Weikersthal L, Clemens MR, Gauler TC, Märten A, Klein S, Kojouharoff G, Barner M, Geissler M, Greten TF, Mansmann U, Kirchner T and Heinemann V: EGFR pathway biomarkers in erlotinib-treated patients with advanced pancreatic cancer: translational results from the randomised, crossover phase 3 trial AIO-PK0104. Br J Cancer 108: 469-476, 2013.

7 Renouf DJ, Tang PA, Hedley D, Chen E, Kamel-Reid S, Tsao MS, Tran-Thanh D, Gill S, Dhani N, Au HJ, Wang L and Moore MJ: A phase II study of erlotinib in gemcitabine refractory advanced pancreatic cancer. Eur J Cancer 50: 1909-1915, 2014.

8 Propper D, Davidenko I, Bridgewater J, Kupcinskas L, Fittipaldo A, Hillenbach C, Klughammer B and Ducreux M: Phase II, randomized, biomarker identification trial (MARK) for erlotinib in patients with advanced pancreatic carcinoma. Ann Oncol 25: 1384-1390, 2014.

9 Weiss GA, Rossi MR, Khushalani NI, Lo K, Gibbs JF, Bharthuar A, Cowell JK and Iyer R: Evaluation of phosphatidylinositol-3kinase catalytic subunit (PIK3CA) and epidermal growth factor receptor $(E G F R)$ gene mutations in pancreaticobiliary adenocarcinoma. J Gastrointest Oncol 4: 20-29, 2013.

10 Preis $\mathrm{M}$ and Korc M: Signaling pathways in pancreatic cancer. Crit Rev Eukaryot Gene Expr 21: 115-129, 2011.

11 Arlt A, Müerköster SS and Schäfer H: Targeting apoptosis pathways in pancreatic cancer. Cancer Lett 332: 346-358, 2013.

12 Skoudy A, Hernández-Muñoz I and Navarro P: Pancreatic ductal adenocarcinoma and transcription factors: role of c-Myc. J Gastrointest Cancer 42: 76-84, 2011.

13 Luo Y, Qiu Z, Tian L, Zhu G, Feng Y, Yi M, Chen X, Wang L, $\mathrm{Li} \mathrm{C}$ and Huang Q: Identification of novel predictive markers for the prognosis of pancreatic ductal adenocarcinoma. Hum Pathol 44: 69-76, 2013.

14 Fountzilas G, Bobos M, Kalogera-Fountzila A, Xiros N, Murray S, Linardou H, Karayannopoulou G, Koutras AK, Bafaloukos D, Samantas E, Christodoulou C, Economopoulos T, Kalogeras KT and Kosmidis P: Gemcitabine combined with gefitinib in patients with inoperable or metastatic pancreatic cancer: a phase II Study of the Hellenic Cooperative Oncology Group with biomarker evaluation. Cancer Invest 26: 784-793, 2008.

15 Altman DG, McShane LM, Sauerbrei W and Taube SE: Reporting Recommendations for Tumor Marker Prognostic Studies (REMARK): explanation and elaboration. PLoS Med 9: e1001216, 2012.

16 Collisson EA, Sadanandam A, Olson P, Gibb WJ, Truitt M, Gu S, Cooc J, Weinkle J, Kim GE, Jakkula L, Feiler HS, Ko AH, Olshen AB, Danenberg KL, Tempero MA, Spellman PT, Hanahan D and Gray JW: Subtypes of pancreatic ductal adenocarcinoma and their differing responses to therapy. Nat Med 17: 500-503, 2011. 
17 Kirby MK, Ramaker RC, Gertz J, Davis NS, Johnston BE, Oliver PG, Sexton KC, Greeno EW, Christein JD, Heslin MJ, Posey JA, Grizzle WE, Vickers SM, Buchsbaum DJ, Cooper SJ and Myers RM: RNA sequencing of pancreatic adenocarcinoma tumors yields novel expression patterns associated with longterm survival and reveals a role for ANGPTL4. Mol Oncol 10: 1169-1182, 2016.

18 Chen DT, Davis-Yadley AH, Huang PY, Husain K, Centeno BA, Permuth-Wey J, Pimiento JM and Malafa M: Prognostic fifteengene signature for early-stage pancreatic ductal adenocarcinoma. PLoS One 10: e0133562, 2015.

19 Bailey P, Chang DK, Nones K, Johns AL, Patch AM, Gingras MC, Miller DK, Christ AN, Bruxner TJ, Quinn MC, Nourse C, Murtaugh LC, Harliwong I, Idrisoglu S, Manning S, Nourbakhsh E, Wani S, Fink L, Holmes O, Chin V, Anderson MJ, Kazakoff S, Leonard C, Newell F, Waddell N, Wood S, Xu Q, Wilson PJ, Cloonan N, Kassahn KS, Taylor D, Quek K, Robertson A, Pantano L, Mincarelli L, Sanchez LN, Evers L, Wu J, Pinese M, Cowley MJ, Jones MD, Colvin EK, Nagrial AM, Humphrey ES, Chantrill LA, Mawson A, Humphris J, Chou A, Pajic M, Scarlett CJ, Pinho AV, Giry-Laterriere M, Rooman I, Samra JS, Kench JG, Lovell JA, Merrett ND, Toon CW, Epari K, Nguyen NQ, Barbour A, Zeps N, Moran-Jones K, Jamieson NB, Graham JS, Duthie F, Oien K, Hair J, Grützmann R, Maitra A, IacobuzioDonahue CA, Wolfgang CL, Morgan RA, Lawlor RT, Corbo V, Bassi C, Rusev B, Capelli P, Salvia R, Tortora G, Mukhopadhyay D, Petersen GM; Australian Pancreatic Cancer Genome Initiative., Munzy DM, Fisher WE, Karim SA, Eshleman JR, Hruban RH, Pilarsky C, Morton JP, Sansom OJ, Scarpa A, Musgrove EA, Bailey UM, Hofmann O, Sutherland RL, Wheeler DA, Gill AJ, Gibbs RA, Pearson JV, Waddell N, Biankin AV and Grimmond SM: Genomic analyses identify molecular subtypes of pancreatic cancer. Nature 531: 47-52, 2016.

20 Smith RA, Tang J, Tudur-Smith C, Neoptolemos JP and Ghaneh $\mathrm{P}$ : Meta-analysis of immunohistochemical prognostic markers in resected pancreatic cancer. Br J Cancer 104: 1440-1451, 2011.

21 Garcea G, Neal CP, Pattenden CJ, Steward WP and Berry DP: Molecular prognostic markers in pancreatic cancer: a systematic review. Eur J Cancer 41: 2213-2236, 2005.
22 Weichert W, Boehm M, Gekeler V, Bahra M, Langrehr J, Neuhaus P, Denkert C, Imre G, Weller C, Hofmann HP, Niesporek S, Jacob J, Dietel M, Scheidereit C and Kristiansen G: High expression of RelA/p65 is associated with activation of nuclear factor-kappaB-dependent signaling in pancreatic cancer and marks a patient population with poor prognosis. Br J Cancer 97: 523-530, 2007.

23 Yang SH, Hsu CH, Lee JC, Tien YW, Kuo SH and Cheng AL: Nuclear expression of glioma-associated oncogene homolog 1 and nuclear factor-kB is associated with a poor prognosis of pancreatic cancer. Oncology 85: 86-94, 2013.

24 te Velde EA, Franke AC, van Hillegersberg R, Elshof SM, de Weger RW, Borel Rinkes IH and van Diest PJ: HER-family gene amplification and expression in resected pancreatic cancer. Eur J Surg Oncol 35: 1098-1104, 2009.

25 Jimeno A, Tan AC, Coffa J, Rajeshkumar NV, Kulesza P, RubioViqueira B, Wheelhouse J, Diosdado B, Messersmith WA, Iacobuzio-Donahue C, Maitra A, Varella-Garcia M, Hirsch FR, Meijer GA and Hidalgo M: Coordinated epidermal growth factor receptor pathway gene overexpression predicts epidermal growth factor receptor inhibitor sensitivity in pancreatic cancer. Cancer Res 68: 2841-2849, 2008.

26 Shin SH, Kim SC, Hong SM, Kim YH, Song KB, Park KM and Lee YJ: Genetic alterations of K-ras, p53, c-erbB-2, and DPC4 in pancreatic ductal adenocarcinoma and their correlation with patient survival. Pancreas 42: 216-222, 2013.

27 Krasinskas AM, Moser AJ, Saka B, Adsay NV and Chiosea SI: $K R A S$-mutant allele-specific imbalance is associated with worse prognosis in pancreatic cancer and progression to undifferentiated carcinoma of the pancreas. Mod Pathol 26: 1346-1354, 2013. 